\title{
Coping with Aviation Noise: \\ Non-Acoustic Factors Influencing Annoyance and Sleep Disturbance from Noise
}

\author{
Susanne Bartels $\mathbb{D}^{D}$, Isabelle Richard $\left(\mathbb{D}\right.$, Barbara Ohlenforst $\mathbb{D}^{D}$, \\ Sonja Jeram (D), Julia Kuhlmann (D), Sarah Benz ${ }^{(D)}$, Dominik Hauptvogel, \\ and Dirk Schreckenberg (D)
}

\begin{abstract}
Annoyance and sleep disturbances due to aircraft noise represent a major burden of disease. They are considered as health effects as well as part of the causal pathway from exposure to long-term effects such as cardiovascular and metabolic diseases as well as mental disorders (e.g. depression). Both annoyance and sleep disturbance are not only determined by the noise exposure, but also to a considerable extent by non-acoustic factors. This chapter summarises the most relevant
\end{abstract}

Detailing and exemplifying notions of Quality of Life, of possible compensation, of the impact of ability to cope with as well as the key factor of trust in authorities

\footnotetext{
S. Bartels $(\varangle) \cdot$ D. Hauptvogel

Sleep and Human Factors Research, Institute of Aerospace Medicine, German Aerospace Center (DLR e.V.), Linder Höhe, 51147 Cologne, Germany

e-mail: susanne.bartels@dlr.de

D. Hauptvogel

e-mail: dominik.hauptvogel@dlr.de

I. Richard

Environnons, 302 route de Mende, 34090 Montpellier, France

e-mail: isabelle.richard@environnons.com

B. Ohlenforst

Royal Netherlands Aerospace Centre NLR, Anthony Fokkerweg 2, 1059 CM Amsterdam, The

Netherlands

e-mail: barbara.ohlenforst@nlr.nl
}

S. Jeram

National Institute of Public Health, Environmental Health, Trubarjeva 2, 1000 Ljubljana, Slovenia e-mail: sonja.jeram@nijz.si

J. Kuhlmann · S. Benz · D. Schreckenberg

ZEUS GmbH, Centre for Applied Psychology, Environmental and Social Research, Sennbrink 46, 58093 Hagen, Germany

e-mail: kuhlmann@zeusgmbh.de

S. Benz

e-mail: benz@zeusgmbh.de

D. Schreckenberg

e-mail: schreckenberg@zeusgmbh.de 
non-acoustic factors and briefly explains their mechanisms on annoyance and sleep as well as the potential to address these factors via intervention methods aiming at the reduction of adverse noise outcomes and an increase in the quality of life of airport residents. Here, the focus is on airport management measures that are considered to help improve the residents' coping capacity. Findings from the ANIMA case studies with regard to main aspects of quality of life in airport residents around European airports are briefly reported and recommendations for a community-oriented airport management are derived.

Keywords Noise annoyance $\cdot$ Sleep disturbance $\cdot$ Quality of life $\cdot$ Coping Non-acoustic factors $\cdot$ Interventions

\section{Annoyance as the Most Common Psychological Effect of Noise and Its Non-Acoustic Influence Factors}

Annoyance due to aircraft noise includes behavioral, emotional and cognitive elements. These are (a) the feeling of disturbance due to noise combined with behavioral responses in order to minimise the disturbance, e.g. closing the window to reduce the noise from outdoors, (b) an emotional/attitudinal response like anger about the noise and a negative attitude towards the noise source, and (c) a cognitive response like the distressful insight that one cannot do much against this unwanted situation.

The multifaceted definition of annoyance already hints at several factors influencing an individual's reaction to noise. Following the research outcomes on noise effects, only about one third of the variations in long-term annoyance judgments can be explained by variables representing the average noise exposure such as $L_{\mathrm{den}}, L_{\mathrm{dn}}$, or $L_{\text {Aeq }}[1]$. Another third of the variation in noise annoyance ratings can be explained by non-acoustic factors, whilst the last third of variance has remained unexplained so far. Non-acoustic factors can be roughly described as those factors "which are not directly connected to the nature of the sound" [2]. Most researchers have defined non-acoustic factors as being those variables that modify, moderate or co-determine responses to noise, but not being part of the causal chain from sound via disturbances to annoyance and further health-related outcomes [e.g., 1]. In order to categorise the manifold non-acoustic factors, it seems plausible to discriminate between factors referring to attitudes and traits of the individuals exposed to noise (personal and social factors) and factors referring to the context of the noise situation (contextual and situational factors) [3]. Moreover, factors exist that refer to the social aspects of the noise management at the noise source. In the following, these factors are listed up and briefly explained with the focus on insights on individual strategies to cope with noise that turn out to be more or less successful. Results from ANIMA [4] underline the importance of considering coping strategies and possibilities more deeply to get a better understanding of the association between aircraft noise exposure and annoyance. 


\section{Personal and Social Factors}

\section{Attitudes, Concerns, and Expectations}

Attitudes, concerns, and expectations belong to the most important non-acoustic factors influencing annoyance [e.g., 5, 6]. Positive evaluations of the noise source, such as the belief that the noise source is important for the local economy, reduce noise annoyance [7] whilst negative attitudes and concerns about the negative health outcomes and in particular the fear of aircraft crashes increase annoyance [e.g., 7, 8]. Aviation-related fears and negative attitudes can contribute even more to aircraft noise annoyance during the past 12 months than the average indicators of noise level such as $L_{\mathrm{den}}, L_{\mathrm{dn}}$, or $L_{\mathrm{Aeq}}$ [e.g., 7, 8]. Annoyance is also enhanced in individuals who believe that the noise situation will worsen in the future [e.g., 8, 9] and in individuals who generally prioritise environmental and silence aspects to economic issues when it comes to airport-related decisions [3, 9].

\section{Noise Sensitivity and Personality Traits}

Noise sensitivity is considered as a stable personality trait with regard to an individual's general susceptibility to noise [10] that may be associated with a more general disposition for experiencing negative emotions, such as anger, tension or anxiety $[11,12]$. Noise sensitivity is considered as one of the most influential variables of noise annoyance besides the above-mentioned attitudes [e.g., 5].

\section{Coping Strategies}

The ability to cope with a noise situation depends on possibilities for control and can differ from one person to another. There are three main ways for a person to deal with noise exposure:

1. Adopt a short-term coping strategy referring to the "here and now", such as strategies that focus on problem-solving or emotions at a given moment. These strategies target the adaptation to the noise exposure via actions to reduce the discomfort induced by the noise, e.g. by cognitive rationalisation, escaping from noise or at least attempting to decrease it, and by covering the noise source [13].

2. Adopt a long-term coping strategy that refers to taking actions against the annoyance and its resolution, for example, by participating in citizens' groups and developing collective strategies to change regulations, by moving to another life place [13] or by simply complaining to the airport.

3. Do not adopt any coping strategies, which can be explained either by the fact that the exposed individuals do not perceive any discomfort, that they are able to delegate the responsibility, or that they feel not to have control over the noise situation and/or that they experience so-called learned helplessness [14]. The 
latter is an adverse mental outcome developed by people who repeatedly feel a real or perceived absence of control over the outcome of a stressful situation. As a consequence, they have learned that they are seemingly unable to control or change anything, and hence are helpless in this situation. Residents who resigned to the stressful noise situation are at higher risk to develop health problems.

In view of this, the ability to cope and coping strategies of an individual are obviously important non-acoustic factors that determine the way of living with noise exposure. And this goes far beyond the mere feeling of annoyance. Coping strategies are therefore considered as a factor involved in the causal pathway from noise exposure to health impacts [15]. However, several questions are not fully resolved: Does the inability to cope have an impact on annoyance as suggested by [16]? Does learned helplessness tend to reinforce negative emotions that would foster annoyance? Future research should bring light in this circle of exposure, annoyance, learned helplessness and health risks. What are the options to break it, e.g. by providing adequate possibilities to improve coping capacities and by having control over a noise situation? There is already evidence that personal control and learned helplessness are relevant intervening factors in the causal chain from noise exposure to annoyance and further health outcomes [e.g. 8, 17]. However, systematic knowledge about successful interventions improving the process of coping with noise is lacking.

\section{Trust in Authorities and Perceived Fairness}

The aforementioned ability to cope and the psychological aspects of perceived control are not only dependent on individual abilities and convictions. The behavior of the airport managers also plays a role including to what extent it is perceived as trustworthy and fair in regard to the affected residents [1, 18]. In this context, many aspects impact on the perception of trust and fairness, but among them is the perception that the airport authorities do their best to avoid unnecessary noise and a perception of an airport communicating honestly and taking the concerns of noise-affected residents seriously. Fairness aspects are strongly related to trust in authority and seem, thus, to be able to reduce annoyance by implementing a consistently fair communication. Fairness aspects have been known to play an important role in various fields (e.g. in the organisational and judicial context) since the 1970s and recently gained attention also in the context of aircraft noise exposure $[19,20]$. Research on fairness has identified a variety of different factors that are important for establishing an environment that allows building trust through fairness. These factors are considered in detail in Chap. 11 and recommendations are made how these can be taken up by airport management. 


\section{Residential Satisfaction}

Residential satisfaction is a frequently studied factor in the socio-psychological field. There is evidence showing that feeling well in the neighbourhood and being content with its (acoustic) appearance and infrastructure impacts annoyance [3, 6, 9]. However, since residential satisfaction also has a strong subjective component and noise effect studies including residential satisfaction are mostly cross-sectional, it is also conceivable that residential satisfaction is rather a consequence of noise affected by annoyance [21].

\section{Demographics}

Although often examined in annoyance research, significant effects of demographic factors such as age, gender, occupational status, educational level, homeownership, dependency on the noise source, and use of the noise source, on annoyance were only seldomly found and if so, they were small [5, 6]. Age has a rather curvilinear effect; i.e. relatively young and relatively old people are less annoyed [5] whilst gender seems to have no influence on annoyance at all. Slightly higher annoyance is reported for people with higher educational level and occupational status, for homeowners, and for people who neither are dependent on the noise source nor use it [5].

\section{Contextual and Situational Factors}

\section{Degree of Urbanisation and Background Noise Exposure}

A typical factor that is lying outside an individual and that persists across different noise situations is the surrounding of an individual. There is at least some evidence that the type of the neighborhood has an influence on annoyance. Noise annoyance seems to be highest in rural areas, followed by suburban, urban, commercial, and industrial areas in decreasing order [3, 22]. Indeed, in an urban area, residents' expectations are congruent with the noise in contrast to rural environments representing a much more peaceful place for people where noise is not expected. The specific situation in rural areas needs to be taken into account for airports surrounded by rather rural areas.

\section{Access to Greenery and Recreational Areas, Appearance of Neighborhood}

Coping with environmental stress as produced by noise requires an individual's resources and coping capabilities to be restored. Access to nature or green areas is 
regarded as allowing such recovery [23]. For example, the availability of vegetation and green spaces as well as the perceived neighborhood greenery can reduce annoyance due to road traffic noise [24, 25] and railway noise [25]. However, green areas per se do not necessarily reduce aircraft noise annoyance. The availability of residential green areas was also shown to increase aircraft noise annoyance for those that were still exposed to aircraft noise [25]. The reason for this might be that aircraft noise is more alien and intrusive in residential areas than road traffic noise [25]. Moreover, the more the neighborhood is perceived as green, the more residents expect a quieter residential environment and might regard aircraft noise as even more intrusive. However, green spaces as compensation strategies can encourage people living under the flight paths to adopt more healthy coping strategies and, thus, improve their quality of life [15]. Moreover, literature shows that the presence of vegetation presented simultaneously with moving water can reduce annoyance as it improves the soundscape $[26,27]$.

\section{Access to a Quiet Side of the Dwelling}

In the context of annoyance due to railway and road traffic, it was shown that the possibility to escape from noise has an annoyance-reducing effect. For example, people residing along a very busy road perceive lower annoyance when their bedroom or living room is directed to a quiet façade [28, 29] that also represents a facet of perceived control over the noise situation. Besides the mere exposure reducing effect, the visual quality of the space (a courtyard or greenery) had an impact on annoyance [30]. Even though aircraft noise cannot be compared to road traffic noise and a quiet façade is per se not feasible, the beneficial effect of the opportunity to escape from noise, e.g. via a quiet room in the building or access to nearby quiet recreational areas, is assumed to be transferable as it offers a measure to cope with the noise.

\section{Differences in Annoyance in Changing Versus Stable Exposure Situations}

A fundamental change in the noise exposure, i.e. an abrupt reduction or increase that is not only due to temporal changes, causes different levels of annoyance than would be expected at airports with a stable exposure. For so-called high-rate change airports that were announced to have or that actually experienced a step change in exposure, for instance because of the opening of a new runway, and, thus, an increase of flight numbers, community annoyance is usually higher than at airports without an experienced or announced change (so-called low-rate change airports) at the same exposure level [31]. Evidence for a change effect exists both for a step-increase and step-decrease in the noise exposure [e.g., 32]. The mechanisms of this effect are not fully understood, yet. Several explanations including a change in residents' attitudes or their retaining of previous and no longer appropriate coping strategies have been discussed [33]. Also, the time it takes the change effect to extinguish is only roughly estimated ranging from several months to several years [33]. 
A step change in noise exposure can also occur due to (unforeseen) events other than operational expansions or re-organisations. In this context, the abrupt reduction of flight numbers during the COVID-19-pandemic seems worth mentioning. The effect of this unforeseen period of decreased aircraft noise exposure on future annoyance after resuming regular operation schemes is currently not clear and warrants consideration in future research on aircraft noise impacts. Relevant questions are, for instance, whether and to what extent airport residents have got "used" to the reduced noise exposure and, thus, have changed their expectation towards acceptable noise levels in their neighbourhood area, to what extent they have changed their habits, for instance with regard to outdoor activities and window-opening behaviour as well as, whether residents' general noise sensitivity and noise tolerance have changed during the lockdown. With regard to the perception of the noise (relief) during the pandemic and future expectations, at least some of these questions are currently targeted in [34].

\section{Temporal Factors of a Noise Situation}

As a result of a busy and noisy working environment, a demand for quiet and restful periods, in particular during the evening and night, has been established in modern industrialised civilisations $[35,36]$. The time of day when the noise occurs is, therefore, a relevant situational influence factor [3,37]. Certain times of a day coincide with specific activities like communication including conversation, socialisation, listening to the radio, and watching TV, prevailing in the afternoon and evening. During the night, the need for recreation and sleep prevails [38]. The early morning hours are likewise regarded as very susceptible to noise due to an individual's psychophysiological adaptation process to the rhythm of the day [36]. Higher annoyance was reported for the weekend [37] most likely due to the fact that the weekend coincides with noise-susceptible activities, above all recreation. In general, the activities contribute to the explanation of why at the same noise exposure level people differ in their short-term annoyance ratings (e.g. per event, hour, or day [3]). In noise effect studies assessing long-term noise responses (e.g. over a period of the past 12 months), activities are specifically addressed in questions on how often or how much these activities were disturbed by noise. In these studies, activity disturbances are regarded as primary reactions to noise preceding annoyance and not as a non-acoustic factor modifying the annoyance without itself depending on noise exposure [e.g. 39].

This last point leads to the method of annoyance assessment. The standardised, general one-item question and scale recommended by the International Commission on the Biological Effects of Noise [ICBEN; 40] is the most common method to assess transportation noise annoyance. Notwithstanding the huge benefits of this internationally standardised method, some deficiencies exist [41, 42] since it is not capable of considering the time of the day the annoyance is experienced (morning, night, etc.). The ICBEN-question refers to the past twelve months, but there is also a bias in memory capacity. Individuals generally tend to remember mostly the very recent or very early experiences [recency and primacy effect, 43]. With regards to the self-assessment of annoyance, research has shown that individuals tend to refer 
to recent situations [44] or the worst situations [45]. Moreover, the semantics a respondent puts under the term of annoyance (loudness, fear, anger, depression) may have an effect as well. As mentioned in the beginning of this chapter, the concept of annoyance covers behavioral, emotional and cognitive elements. Acknowledging this, the ICBEN question makes an attempt to capture the multidimensionality of the concept via only one single-item question that combines the aspects "annoyance", "disturbance", and "bother". Whether these concepts can really be subsumed under the general construct of annoyance, is disputable. It could be valuable in further research to complement the ICBEN-question by additional standardised questions to better match the concept of annoyance [46].

\section{Social Aspects of the Noise Management}

As described, trust in authorities and perceived fairness play a major role in coping with aircraft noise exposure. Their role can be generally extended to the experience of a neighbourly relationship with the airport and its activities. Social aspects of noise management and noise exposure are non-acoustic factors that may additionally affect noise annoyance. Examples of such social, non-acoustic factors are:

- The effect of noise insulation on noise-induced annoyance is evident [6]. Although exposure from outdoor noise diminished, evidence for an annoyance-reducing effect of noise insulation is mixed. The mere fact that noise insulation has been installed at home did not affect annoyance [9], but being satisfied with the sound attenuation of insulation windows at home had an effect [47]. Results from ANIMA show that insulation scheme procedure is not considered by residents as a relevant solution depending on the season and the regional climate. It is rather perceived as a necessary measure but not sufficient to reduce their discomfort regarding aircraft noise [4].

- A shift or redistribution of noise exposure across populations. Such operational measures change the exposure of the affected people, but they are also related with non-acoustic factors described above, such as the perception that noise authorities care for the residents' needs and health. The distribution of costs and benefits that fall across the population might be uneven and perceived as unfair [4]. To solve this problem, rigorous and accepted methods for balancing uneven costs and benefits of aviation are required [48].

Given the nature of those social non-acoustic factors, fairness beliefs and trust in authorities are potentially addressable by a community-oriented airport management, meaning that interventions that are undertaken are accompanied by consultation, education and communication as well as community engagement. 


\section{Sleep Disturbance as the Most Common Neuro-Behavioral and Physiological Effect of Noise and Its Non-Acoustic Influence Factors}

Disturbances of sleep are a major adverse reaction to nocturnal noise and can be manifested by changes in the sleep depth and sleep continuity and, as a consequence of this less restorative sleep, by fatigue and a reduced cognitive performance during the following day. As already described in Chap. 9, sudden noisy events have hinted at threats in the early history of humankind. It was necessary that humans were able to react quickly, including when asleep. Noisy events are, therefore, subliminally perceived and evaluated even during sleep and can provoke physiological reactions such as an awakening, bringing an individual back to a conscious state. The extent of the sleep disturbance per night depends on the number of noise events and each one's acoustic properties, such as the level of the noise event, or the speed that the level rises, which is an indicator of how fast the event is approaching. Potentially threatening noise events consequently cause a reaction with higher probability [49]. Whether a noise event causes an awakening, however, does not only depend on its acoustic properties but also on situational and personal factors.

\section{Situational Factors}

In the framework of the ANIMA-project, a standardised sleep model has been developed that describes the probability for an aircraft noise-induced awakening from sleep that does not only include acoustic features of the aircraft noise event (e.g. maximum level, duration, speed of the level rise) but also situational factors [50]. Whether an individual wakes up is influenced by the duration it has already been asleep. With increasing sleep time, the internal biological drive for sleep decreases and sleep becomes more susceptible for disturbances, as it is particularly the case in the early morning hours. When sleep pressure is low, the human organism is not only prone for an awakening but also has greater problems to fall asleep again [49]. The time spent asleep is also connected to the prevailing sleep stages, which are again influencing the probability for an aircraft noise to evoke an awakening reaction. It is less likely to awake from deep sleep stages than from light sleep stages. Moreover, whether an aircraft noise event causes an awakening or not is influenced by the background sound pressure level at the time when the noise event occurs. The probability to awake is enhanced when the aircraft noise event stands out from the background noise. 


\section{Personal Factors}

Personal factors such as age can have an influence on sleep. Sleep rhythm and the duration spent in the different sleep stages change during a lifespan. With increasing age, the amount of deep sleep decreases [51]. Children are less likely to awake than adults at the same sound pressure level [52] whilst the elderly are assumed to be at higher risks for aircraft noise induced-sleep disturbances. Age is therefore included in the ANIMA standardised sleep model [50]. However, the effect of aircraft noise on elderly people has sparsely been investigated. An effect of age on self-rated sleep disturbances due to aircraft noise has recently been shown [53]. Gender is not a relevant influence factor of the probability to awake due to aircraft noise according to the ANIMA standardised sleep model [50] and other studies [54]. Additionally, self-rated sleep disturbance due to aircraft noise seems not to be remarkably affected by gender [53].

Noise sensitivity is assumed to be an important non-acoustic factor for both selfrated sleep disturbance and acute physical reactions to transportation noise [55]. However, the evidence of differences between noise sensitive versus non-sensitive individuals is scarce and systematic analyses of the effect of noise sensitivity on physiologically measured sleep are lacking [54].

The extent of the impact of personal factors may also depend on the measurement of sleep disturbance. Asking for self-rated sleep disturbances due to, e.g. aircraft noise, leaves room for personal attitudes, emotions and knowledge similarly as it is the case for annoyance judgments. The relation between self-rated sleep disturbance assessed without any reference to aircraft noise and the exposure level is weaker than when aircraft noise is explicitly mentioned as a potential source of the sleep disturbance [49]. But also for physiologically measured sleep disturbances and awakenings, the effect of aircraft noise exposure differs remarkably between individuals. These differences are not fully explainable by gender, age, and noise sensitivity [54]. Attitudes towards aviation may be a source for these differences [56].

\section{Relation Between Sleep Disturbance and Annoyance}

As described above, annoyance can evolve from the repeated disturbance of intended activities including sleeping. Annoyance is therefore sometimes regarded as one secondary effect of sleep disturbance as well as the resulting perception of fatigue, decreased cognitive functioning and changed mood [35]. Evidence exists that (shortterm) annoyance assessed in the morning and with regard to the past night is related to the past night's aircraft noise exposure [57]. Likewise, an association between nocturnal aircraft noise exposure and cognitive functioning [58] and with self-rated tiredness in the morning [59] was found. Nevertheless, whether annoyance judgments are covering experiences of sleep disturbance or whether noise annoyed residents suffer from sleep disturbance more often, is not clear yet [60]. Presumably, the 
relation between sleep disturbance and annoyance is reciprocal. Poor sleep from nocturnal noise can affect the next day's mood, performance and well-being and as a consequence promote annoyance. However, feeling annoyed due to aircraft noise during the day may affect sleep as well since annoying/upsetting situations that were experienced during the day can be processed during sleep.

\section{Role of Non-Acoustic Factors for Aircraft Noise Interventions}

A crucial conclusion that can be drawn from the research on the effect of nonacoustic factors so far, is that those factors have the largest impact on the noise response that tackle the individual's capacity to cope with the noise. As described above, control over the noise situation or aviation-related decisions can strengthen one's coping capacity. The perception of having control covers two components: On the one hand, direct and immediate measures can be undertaken, e.g., controlling a noise situation via closing windows, or, having access to respite locations and periods. On the other hand, people can have indirect control via being represented in noise-related decision-making processes and, thereby, having voice either personally or through trusted authorities that act and decide on the residents' behalf. In that sense, it is important to distinguish long-term from short-term coping strategies in the same way that we differentiate between long-term and short-term annoyance. Short-term annoyance is associated with short-term coping strategies and can strongly influence the discomfort felt in a specific situation. In contrast, long-term annoyance is associated with long-term coping strategies and can have on the long run a strong impact on residents' health. By improving the ability of residents to cope with their noise exposure in the long-term and not only at a given time, interventions could reduce residents' annoyance. Residents' coping capacity is assumed to be enhanced by giving them decision-making power, by acknowledging them as knowledgeable of their experiences in the field of noise exposure, by acknowledging and considering the environmental and the health costs of each planned project, etc. Thus, enhancing the coping capacity may tackle certain outcomes that are related to annoyance, such as improving residents' health, creating trust and transparency between airport operators, authorities and residents, and saving more time and energy in raising aviation-related projects.

Further to the importance of perceived control for coping with noise, the possibility of recreation is crucial as it allows for restoring coping capacities that are diminished when dealing with ongoing stress. Besides continuously reducing aircraft noise exposure as well as implementing interventions targeting non-acoustic factors, noise management should focus on increasing people's perceived control and coping capacities and allow for space and time for recreation.

Therefore, some authors have categorised non-acoustic factors with regard to the strength of importance for aircraft noise responses, in particular annoyance, and 
the modifiability by means of interventions [2, 61, 62]. A review and summary were produced within ANIMA [63]. For this chapter, we revised and enhanced this system of categorising non-acoustic factors by adding the assessment of the effect of non-acoustic factors on sleep-disturbance and exemplifying how the factors can be addressed in aircraft noise management (see Table 1).

Even when aircraft noise interventions such as those mentioned in Table 1 aim at reducing adverse noise effects addressing both acoustic as well as nonacoustic factors of, for example, annoyance or sleep disturbance, airport operators and aviation-related authorities have to be aware that the aircraft noise management activities have an impact on communities' quality of life in general. This is true for all airport activities. Therefore, in the next section, we will describe main areas of people's quality of life and link them to airport/aviation activities that potentially address these quality of life facets in an airport region.

\section{Role of Airport Interventions on Quality of Life in Airport Regions}

There are a variety of definitions and frameworks relating to quality of life. The WHO defines quality of life (QoL) as "an individual's perception of their position in life in the context of the culture and value systems in which they live and in relation to their goals, expectations, standards and concerns" [65, p 1], which is a broad conceptualisation that emphasises a person's motives and perceptions. Most of previous research has been conducted on the interaction between noise exposure and annoyance or health-related effects. The innovative approach within the ANIMA project addressed the relationship between aircraft noise exposure, noise annoyance, and QoL. It is essential to understand the impact of aircraft noise management and noise-related interventions that can influence different dimensions of QoL next to health-related outcomes. Currently, little is known about the quality of life dimensions and their interactions that are important for residents around airports. For the purpose of addressing issues that communities in the vicinity of airports face, one existing framework, the EUROSTAT approach [66], was considered best fit and adapted in the ANIMA project [67]. The EUROSTAT framework considers nine QoL dimensions with specific indicators for measuring QoL: material living conditions, productive or main activity (job), health, education, leisure, economic security and physical safety, governance and basic rights, natural and living environment, and overall experience of life. To some extent the different dimensions overlap and interdependencies are likely to occur.

Within the ANIMA project, a study was conducted in four different European airport regions in an attempt to capture crucial aspects of residents' quality of life [4]. A re-analysis of recently collected data from a survey conducted around Schiphol revealed that participants living near Schiphol Airport are generally satisfied with 
Table1 Role of non-acoustic factors in aircraft noise management

\begin{tabular}{|c|c|c|c|c|}
\hline \multirow[t]{2}{*}{ Factor } & \multicolumn{2}{|l|}{ Effect on ... } & \multirow[t]{2}{*}{ Address-ability } & \multirow{2}{*}{$\begin{array}{l}\text { Starting points for } \\
\text { modification/improvement }\end{array}$} \\
\hline & Annoy-ance & Sleep & & \\
\hline \multicolumn{5}{|l|}{$\begin{array}{l}\text { Personal and } \\
\text { social factors }\end{array}$} \\
\hline $\begin{array}{l}\text { Attitudes, } \\
\text { concerns, } \\
\text { expectations }\end{array}$ & + & + & +- & \multirow[b]{2}{*}{$\begin{array}{l}\text { Communication and engagement } \\
\text { campaigns accompanying } \\
\text { interventions and projects (e.g. } \\
\text { operational changes) and raising } \\
\text { awareness in both airport } \\
\text { management and the affected } \\
\text { communities; dialogue forum and } \\
\text { information service; } \\
\text { acknowledgement of adverse health } \\
\text { and environmental outcomes by } \\
\text { airport management; transparent } \\
\text { complaint management; } \\
\text { compensation programs with the } \\
\text { engagement of communities, e.g., } \\
\text { via compensation that is selectable } \\
\text { by the residents }\end{array}$} \\
\hline $\begin{array}{l}\text { Trust in } \\
\text { authorities, } \\
\text { perceived fairness }\end{array}$ & + & $+?$ & + & \\
\hline Coping strategies & + & $?$ & +- & $\begin{array}{l}\text { Communication and engagement } \\
\text { campaigns; dialogue forum and } \\
\text { information service; transparent } \\
\text { complaint management; education } \\
\text { on coping possibilities; respite } \\
\text { times with dynamic noise maps } \\
\text { with information on planned air } \\
\text { traffic around airports making noise } \\
\text { exposure predictable and enabling } \\
\text { residents to plan noise-susceptible } \\
\text { (outdoor) activites }\end{array}$ \\
\hline $\begin{array}{l}\text { Residential } \\
\text { satisfaction }\end{array}$ & +- & $+?$ & + & $\begin{array}{l}\text { Community engagement in design } \\
\text { of neighborhood appearance; } \\
\text { land-use planning; provision of } \\
\text { access to greenery and quiet } \\
\text { recreational areas }\end{array}$ \\
\hline Demographics & +- & +- & +- & $\begin{array}{l}\text { Age: Land-use planning regarding } \\
\text { vulnerable groups (children, } \\
\text { elderly, i.e. placement of } \\
\text { kindergartens, schools, nursing } \\
\text { homes) } \\
\text { House ownership: House purchase } \\
\text { scheme, noise exposure schemes }\end{array}$ \\
\hline
\end{tabular}


Table1 (continued)

\begin{tabular}{|c|c|c|c|c|}
\hline \multirow[t]{2}{*}{ Factor } & \multicolumn{2}{|l|}{ Effect on ... } & \multirow[t]{2}{*}{ Address-ability } & \multirow{2}{*}{$\begin{array}{l}\text { Starting points for } \\
\text { modification/improvement }\end{array}$} \\
\hline & Annoy-ance & Sleep & & \\
\hline \multicolumn{5}{|l|}{$\begin{array}{l}\text { Contextual and } \\
\text { situational } \\
\text { factors }\end{array}$} \\
\hline $\begin{array}{l}\text { Degree of } \\
\text { urbanisation \& } \\
\text { background noise }\end{array}$ & + & + & - & \multirow{2}{*}{$\begin{array}{l}\text { Improved noise-sensitive land use } \\
\text { planning legislation; access to } \\
\text { recreational, calm and green areas; } \\
\text { operational interventions }\end{array}$} \\
\hline $\begin{array}{l}\text { Access to } \\
\text { greenery \& } \\
\text { recreational areas, } \\
\text { appearance of } \\
\text { neighborhood }\end{array}$ & +- & $?$ & + & \\
\hline $\begin{array}{l}\text { Access to a quiet } \\
\text { side of the } \\
\text { dwelling }\end{array}$ & + & + & +- & $\begin{array}{l}\text { Insulation programs; indoor design } \\
\text { of dwellings and arrangement of } \\
\text { rooms (e.g. bedrooms); sound } \\
\text { adaptive buildings and urban design }\end{array}$ \\
\hline $\begin{array}{l}\text { Time/day when } \\
\text { noise occurs }\end{array}$ & + & + & + & $\begin{array}{l}\text { Operational interventions (respite } \\
\text { time, night curfews); dynamic } \\
\text { noise maps with information on } \\
\text { planned air traffic around airports } \\
\text { making noise exposure predictable } \\
\text { and enabling residents to plan } \\
\text { noise-susceptible (outdoor) } \\
\text { activites; raising awareness for the } \\
\text { requirement of noise respite times }\end{array}$ \\
\hline \multicolumn{5}{|l|}{$\begin{array}{l}\text { Social aspects of } \\
\text { noise } \\
\text { management }\end{array}$} \\
\hline Insulation & + & + & + & \multirow[b]{2}{*}{$\begin{array}{l}\text { Consultation and community } \\
\text { engagement; insulation programs } \\
\text { engaging communities, e.g., via } \\
\text { selectable insulation measures; } \\
\text { dynamic noise maps with } \\
\text { information for planned air traffic } \\
\text { around airports }\end{array}$} \\
\hline $\begin{array}{l}\text { Operational } \\
\text { intervention }\end{array}$ & + & + & + & \\
\hline
\end{tabular}

Adapted from $[2,61,62]$ and modified according to the review presented in this chapter and results obtained from ANIMA studies [4, 64]

Note + evidence for an effect or addressability is given, - evidence for an effect or addressability is not given, +- evidence for an effect or addressability is ambivalent, ? evidence for an effect or addressability has not yet been examined, + ? an effect is assumed but has not yet been examined. 
their residential area. However, there is a difference in people's residential satisfaction depending on the noise contour they live in. Although all groups were on average either "satisfied" or "very satisfied" with their residential area, the results suggest that the exposure to higher levels of aircraft noise may negatively affect people's residential satisfaction. Similar results were found conducting focus groups around Marseille Airport. Overall, participants were satisfied with their living environment, but aircraft noise exposure and other negative effects of air traffic were mentioned as aspects of their residential area negatively affecting their QoL. People living around Frankfurt Airport were asked about their understanding of quality of life. They mentioned aspects such as family, health, nature, the social and living environment, and security. Most participants stated that their living environment has a crucial impact on their quality of life, which can be both positive (nature) and negative (noise). When asked about their living environment, residents living near Heathrow Airport mentioned, for example, being concerned about air quality and noise pollution. With respect to quality of life, they rated the existing infrastructure and nature as positive aspects and mentioned negative aspects such as road traffic and an increase in aircraft noise.

At the end of 2020, a survey of various factors related to QoL and the impact of aviation during Covid-19 was carried out to gain a better understanding of the effect of less air traffic on residents' perception of aviation. To this end, a group of people living close to Schiphol was compared with a group living around the city of Utrecht. The results suggest that the group living around Utrecht (placed nearer to the local airport) takes a more negative view of aviation than the group living near Schiphol (living further away from the local airport). This negative affinity with aviation is also supported by other recent Dutch studies [e.g., 68].

In the section above, it was explained that non-acoustic factors of annoyance referring to attitudes, concerns, personal traits, residential satisfaction and demographics of the person exposed to aircraft noise, affect the perception of annoyance. Results from case studies conducted within ANIMA suggest an interaction of several of those non-acoustic factors and a direct impact on people's QoL. If people were exposed to higher noise levels they reported lower residential satisfaction and other negative effects of air traffic seemed to negatively affect their QoL. When noise exposure increases, the balance between advantages and disadvantages of the noise exposure may shift. People living closest to airports do not necessarily have more benefits such as mobility, or economic safety.

\section{Natural and Living Environment}

High exposure to aircraft noise may have a negative impact on residents' natural and living environment as it disturbs people's daily activities. People might be more concerned about the noise exposure, increasing air traffic, lowering housing prices, lower air quality, negative developmental effects in children and the feeling of shame for the noise. When people feel ashamed in front of their friends or families for the 
noise exposure at their homes, a direct negative impact on their social life is likely to result. Non-acoustic factors such as increased concerns may alter people's well-being, impact their health and their social life and in that way affect their QoL.

\section{Productive or Main Activity}

It seems that an economic relationship with the airport creates fewer negative associations with aviation. Most people working for the aviation industry trust their company and they identify themselves with aviation and their work. Their residential satisfaction may be high and together with less concerns their perception of noise annoyance may be limited. In this way, non-acoustic factors related to noise annoyance are intertwined with the residents' QoL.

\section{Education and Leisure}

There are dimensions where airports can have a direct positive impact on their neighborhood. Airports can have a beneficial take on improving quality of life in adding value to certain aspects such as structural improvements (e.g. infrastructure), supporting leisure activities in sponsoring training gear for local sports clubs, providing access to education, knowledge, public activities, leisure and cultural places, general aviation or drone areas. Research indicated that children living in the vicinity of airports show impaired reading abilities, explained by aircraft noise exposure [69]. Creating access to education, knowledge, libraries and learning facilities may be a way to respond to impaired reading abilities or even counteract adverse effects. Regarding leisure time, as mentioned in the section on the non-acoustic factor of "Access to greenery and recreational areas" the possibility to recreate is able to minimise annoyance. In addition, it is also an important aspect of QoL, both for children, and adults in general as it allows physical activities, learning by playing, it improves health and allows for recovery from daily stress.

Using a concept like QoL to assess the impact of an airport on its surroundings allows for observing both positive and negative consequences that are linked to the airport. Next to decreasing people's stress response to noise, i.e. annoyance, by reducing the noise exposure, it can be useful to improve their QoL as this can help increase people's coping capacities. While many interventions aimed at reducing or minimising noise responses in the past, only few interventions additionally focused on improving quality of life specifically. Although not specifically addressed, existing interventions can have unintended (positive) side effects on residents' QoL. Several studies have linked aircraft noise annoyance to health-related QoL [e.g. 16].

In addition, QoL factors might be positively influenced in an indirect way. By improving residents' QoL, airports can affect non-acoustic factors of annoyance such as concerns, negative attitudes and residential satisfaction. Building on the 
relationship and creating trust requires frequent and transparent communication. Well-developed community engagement strategies should strongly focus on establishing a good relationship and not only be applied when an operational change or procedure is planned. Another important aspect is commitment to engage residents. When carrying out community engagement actions, people's opinions and the local situation need to be considered. Feedback should be provided and information on the progress of investigated topics should be reported back to the residents. When airport management engages and establishes good relationships with their neighborhood the feeling of being in control and empowerment might be granted to the residents. Trust in aviation and the related authorities can improve people's QoL. When considering QoL and aiming at improvements in QoL dimensions/aspects through interventions, it is necessary to focus on local characteristics and tailor interventions to the conditions and local issues of the targeted area.

\section{Conclusions: How to Deal with Non-Acoustic Factors in Aircraft Noise Management?}

This chapter has highlighted the importance of considering non-acoustic factors in aviation-related decision-making and management. The Balanced Approach to aircraft noise management of the International Civil Aviation Organisation (ICAO) has already adopted the idea of considering non-acoustic factors. Consideration of people's views (via improved communication and information access as well as consultation) has been emphasised to be involved in each of the four existing elements (a) reduction of noise at source, (b) land-use planning and management, (c) noise abatement operational procedures, and (d) operating restrictions [70]. The goal is to address specific noise problems at individual airports in order to identify the noiserelated measures that achieve cost-effective maximum environmental benefits using objective and measurable criteria. Within the ANIMA project, several case studies at small and large airports have been carried out in order to investigate the potential of best practice interventions in aircraft noise management that address non-acoustic factors.

The case studies revealed the importance of involving all stakeholders, such as representatives of airport operators, local communities, civil aviation authorities and policy makers. Transparent policy of noise management and community engagement showed to be of crucial importance in reaching promising interventions aiming at reducing annoyance and enhancing quality of life of citizens.

The results of the case studies confirmed what is theoretically derived: community engagement has to be understood as a possibility for residents to not only have a voice, but above all, to take part in the decision-making process. Their voice has to count rather than be only consultative. This is confirmed by experienced aircraft noise campaigners such as [71] when he stated in his reflection of 20 years of campaigning: "The key thing for airports to address is the local area-specific issues which concern 
the campaigners. And communities need to be involved in shaping these solutions, particularly at times of change" [71, p 3].

For instance, some results of ANIMA [64] showed that people describe an ideal relationship with the airport as sharing information, fairness, mediation, trust as well as recognition. On a more practical level, options like open and transparent dialog and communication, benefits, being involved, performance and compensation can help to create this ideal relationship. Specifically, these ideas translate into improvements directly affecting noise reduction, noise compensation, and communication. All in all, communication and engagement are crucial elements of aircraft noise management for addressing non-acoustic factors of aircraft noise annoyance and sleep disturbances. They are also good starting points to enhance residents' quality of life as they have the capacity to lower annoyance.

This chapter has demonstrated the immense effect that non-acoustic factors have on sleep disturbance, annoyance and more broadly on quality of life. Overall, it appears necessary to revise the manner in which annoyance is assessed by adding more standardised questions, and to better investigate the role of coping strategies and the ability to cope with noise and on the capacity to reduce health impacts. The proposed starting points of interventions that address the non-acoustic factors (Table 1) are derived from evidence mainly on findings of non-acoustic contributors to annoyance. In part, it is assumed that most of these non-acoustic factors also affect sleep disturbances. Whether the suggested interventions listed in Table 1 actually have a beneficial effect on citizens' quality of life including a decrease in sleep disturbance and annoyance has to be systematically examined in evaluation studies. Such studies should be a fixed part of the implementation of aircraft noise interventions.

Chapter 11 elaborates more on this and presents criteria and standards to guide the establishment of successful and beneficial communication and engagement. At the end of this chapter, we point out that the evaluation and its results themselves address non-acoustic factors as, once communicated, the evaluation contributes to the building of trust in authorities, perceived fairness and self-regulation (being part of a-hopefully successful—story).

\section{References}

1. Guski R (1999) Personal and social variables as co-determinants of noise annoyance. Noise Health 3:45-56

2. Asensio C, Gasco L, de Arcas G (2017) A review of non-acoustic measures to handle community response to noise around airports. Curr Pollution Rep 3:230-244. https://doi.org/10.1007/s40 726-017-0060-x

3. Bartels S (2014) Aircraft noise-induced annoyance in the vicinity of Cologne/Bonn Airport. The examination of short-term and long-term annoyance as well as their major determinants. Technische Universität Darmstadt (Dissertation). http://tuprints.ulb.tu-darmstadt.de/4192/

4. Kuhlmann J, Rajé F, Richard I, Ohlenforst B (2020) Deliverable 3.6 evaluations of previous interventions in improving quality of life. Zenodo. https://doi.org/10.5281/zenodo.4288282 
5. Miedema HME, Vos H (1999) Demographic and attitudinal factors that modify annoyance from transportation noise. J Acoust Soc Am 105(6):3336-3344

6. Fields JM (1993) Effect of personal and situational variables on noise annoyance in residential areas. J Acoust Soc Am 93(5):2753-2763

7. Schreckenberg D, Meis M, Kahl C, Peschel C, Eikmann T (2010) Aircraft noise and quality of life around Frankfurt Airport. Int J Environ Res Public Health 7:3382-3405. https://doi.org/ 10.3390/ijerph7093382

8. Kroesen M, Molin EJE, van Wee B (2008) Testing a theory of aircraft noise annoyance: a structural equation analysis. J Acoust Soc Am 123(6):4250-4260

9. Wirth K (2004) Lärmstudie 2000-Die Belästigungssituation im Umfeld des Flughafens Zürich. Dissertation [Swiss Noise Study 2000: The status quo of annoyance in the vicinity of the airport Zurich (doctoral dissertation)], Universität Zürich, Schweiz

10. Zimmer K, Ellermeier W (1999) Psychometric properties of four measures of noise sensitivity: a comparison. J Environ Psychol 19:295-302

11. Stansfeld SA (1992) Noise, noise sensitivity and psychiatric disorder: epidemiological and psychophysiological studies. Psychol Med Monogr Suppl 22:1-44

12. Persson R, Björk J, Ardö J, Albin M, Jakobsson K (2007) Trait anxiety and modeled exposure as determinants of self-reported annoyance to sound, air pollution and other environmental factors in the home. Int Arch Occup Environ Health 81(2):179-191

13. Levy-Leboyer C, Moser G (1987) Individual differences in noise annoyance: four explanations. In: Koelega HS (ed) Environmental annoyance: characterisation, measurement and control. Elsevier, Amsterdam, The Netherlands, pp 293-299

14. Seligman MEP (1975) Helplessness: on depression, development, and death. W. H. Freeman, San Francisco, USA

15. Föllmer J, Moore G, Kistemann T (2020) Urban parks as nature-based solutions for improved well-being under the flight paths: a soundscape analysis in the vicinity of Heathrow Airport, EGU General Assembly 2020, Online, 4-8 May 2020, EGU2020-17661. https://doi.org/10. 5194/egusphere-egu2020-17661

16. Schreckenberg D, Benz S, Belke C, Möhler U, Guski R (2017) The relationship between aircraft sound levels, noise annoyance and mental well-being: an analysis of moderated mediation. In: Proceedings of 12th ICBEN congress on noise as a public health problem, Zurich, Switzerland

17. Hatfield J, Job RFS, Hede AJ, Carter NL, Peploe P, Taylor R, Morrell S (2002) Human response to environmental noise: the role of perceived control. Int J Behav Med 9(4):341-359

18. Stallen PJM (1999) A theoretical framework for environmental noise annoyance. Noise Health $1(3): 69-79$

19. Maris E (2008) The social side of noise annoyance (De sociale kant van geluidhinder). Doctoral thesis, Department of Social en Organisational Psychology/Cognitive Psychology, Faculty of Social and Behavioural Sciences, Leiden University, The Netherlands

20. Liebe U, Preisendörfer P, Bruderer Enzler H (2020) The social acceptance of airport expansion scenarios: a factorial survey experiment. Transp Res D Transp Environ 84:102363. https://doi. org/10.1016/j.trd.2020.102363

21. Kroesen M, Molin EJE, Miedema HME, Vos H, Janssen SA, van Wee B (2010) Estimation of the effects of aircraft noise on residential satisfaction. Transp Res Part D: Transp Environ 15(3):144-153. https://doi.org/10.1016/j.trd.2009.12.005

22. Lercher P, de Greve B, Botteldooren D, Rüdisser J (2008) A comparison of regional noiseannoyance-curves in alpine areas with the European standard curves. Paper presented at the 9th International Congress on Noise as a Public Health Problem, July 21-25, 2008, Foxwoods, CT, USA

23. Hartig T, Mitchell R, de Vries S, Frumkin H (2014) Nature and health. Annu Rev Public Health 35:207-228

24. Van Renterghem T (2019) Towards explaining the positive effect of vegetation on the perception of environmental noise. Urban Forestry Urban Greening 40:133-144

25. Schäffer B, Brink M, Schlatter F, Vinneau D, Wunderli, JM (2020) Residential green is associated with reduced annoyance to road traffic and railway noise but increased annoyance to aircraft noise exposure. Environ Int 143:105885 
26. Lugten M, Karacaoglu M, White K, Kang J, Steemers K (2018) Improving the soundscape quality of urban areas exposed to aircraft noise by adding moving water and vegetation. $\mathrm{J}$ Acoust Soc Am 144(5):2906-2917. https://doi.org/10.1121/1.5079310

27. Yu L, Kang J (2010) Factors influencing the sound preference in urban open spaces. Appl Acoust 71(7):622-633

28. Bodin T, Bjork J, Ardö J, Albin M (2015) Annoyance, sleep and concentration problems due to combined traffic noise and the benefit of quiet side. Int $\mathrm{J}$ Environ Res Public Health $12: 1612-1628$

29. De Kluizenaar Y, Janssen SA, Vos H, Salomons EM, Zhou H, van den Berg F (2013) Road traffic noise and annoyance: a quantification of the effect of quiet side exposure at dwellings. Int J Environ Res Public Health 10:2258-2270

30. Van Kamp I, Brown AL, Schreckenberg D (2019) Soundscape approaches in urban planning: implications for an intervention framework. In: Proceedings of the 23rd international congress on acoustics, 9-13 Sept 2019. Aachen, Germany, pp 405-410

31. Guski R, Schreckenberg D, Schuemer R (2017) WHO environmental noise guidelines for the European Region: a systematic review on environmental noise and annoyance. Int J Environ Res Public Health 14:1539. https://doi.org/10.3390/ijerph14121539

32. Brink M, Wirth KE, Schierz C, Thomann G, Bauer G (2008) Annoyance responses to stable and changing aircraft noise exposure. J Acoust Soc Am 124(5):2930-2941. https://doi.org/10. $1121 / 1.2977680$

33. Brown AL, van Kamp I (2009) Response to a change in transport noise exposure: competing explanations of change effects. J Acoust Soc Am 125(2):905-914. https://doi.org/10.1121/1. 3058636

34. Marshall B, Xypolia K, Walford A (2020) Aviation noise during lockdown. Ipsos MORI Report for the ICCAN, report no. 20-036970-01. https://iccan.gov.uk/wp-content/uploads/ 2020_10_08_Aviation_noise_during_lockdown_Ipsos_survey_report_for_ICCAN-min.pdf

35. Porter ND, Kershaw AD, Ollerhead JB (2000) Adverse effects of night-time aircraft noise (Rep. No. 9964). UK Civil Aviation Authority, London, UK

36. Hoeger R (2004) Aircraft noise and times of day: possibilities of redistributing and influencing noise exposure. Noise Health 6(22):55-58

37. Schreckenberg D, Meis M (2006) Gutachten Belästigung durch Fluglärm im Umfeld des Frankfurter Flughafens-Endbericht [Annoyance due to aircraft noise in the vicinity of Frankfurt Airport-Final report]. ZEUS GmbH, Hörzentrum Oldenburg, Bochum, Oldenburg, Germany

38. Fields JM (1985) The timing of noise-sensitive activities in residential areas, NASA Contractor Report 177937 (Rep. No. NASA Contractor Report 177937). The Bionetics Corporation, Hampton, Virginia, USA

39. Flindell I, Le Masurier P, Le Masurier H (2021) Resolving uncertainties in understanding community attitudes to aircraft noise. Appl Acoust 178:108032

40. Fields JM, de Jong RG, Gjestland T, Flindell IH, Job RFS, Kurra S et al (2001) Standardized general-purpose noise reaction question for community noise surveys: research and a recommendation. J Sound Vib 242(4):641-679

41. Sparrow V, Gjestland T, Guski R, Richard I, Basner M, Hansell A, de Kluizenaar Y, Clark C, Janssen S, Mestre V, Loubeau A, Bristow A, Thanos S, Vigeant M, Cointin R (2019) Aviation noise impacts. White Paper. State of the science 2019: aviation noise impacts. Chapter 2 in ICAO Environmental report. https://www.icao.int/environmental-protection/Documents/Sci entificUnderstanding/EnvReport2019-WhitePaper-Noise.pdf

42. Richard I (2017) Aircraft annoyance: a psychosocial approach. Presentation in the ISG Aviation Noise Impacts workshop. OACI, November 1-3, 2017, Montréal, Canada

43. Ebbinghaus H (1913) On memory: a contribution to experimental psychology. Teacher College, New York

44. Brink M, Schreckenberg D, Vienneau D, Cajochen C, Wunderli JM, Probst-Hensch N, Röösli M (2016) Effects of Scale, question location, order of response alternatives, and season on selfreported noise annoyance using ICBEN Scales: a field experiment. Int J Environ Res Public Health 13(11):1163. https://doi.org/10.3390/ijerph13111163 
45. Hallmann S, Guski R, Schuemer R (2001) Cognitive Processes in global noise annoyance judgments. Paper presented at the 30th international congress and exposition on noise control engineering, August 28-30, 2001. The Hague, The Netherlands

46. Schreckenberg D, Belke C, Spilski J (2018) The development of a multiple-item annoyance scale (MIAS) for transportation noise annoyance. Int J Environ Res Public Health 15(5):971. https://doi.org/10.3390/ijerph15050971

47. Kastka J (1999) Untersuchung der Fluglärmbelastungs-und Belästigungssituation der Allgemeinbevölkerung der Umgebung des Flughafen Frankfurt [Examination of aircraft noise exposure and aircraft noise-induced annoyance in the vicinity of Frankfurt Airport], Report. Heinrich-Heine-Universität Düsseldorf, Germany

48. Upham P, Maughan J, Raper D, Thomas C (eds) (2003) Towards sustainable aviation. Earthscan Publication, New York, USA

49. Basner M, McGuire S (2018) WHO environmental noise guidelines for the European region: a systematic review on environmental noise and effects on sleep. Int J Environ Res Public Health 15:519

50. Müller U (2019) ANIMA D3.2 - Development of indicators for night noise protection zones. Zenodo. https://zenodo.org/record/5517783

51. Ohayon MM, Carskadon MA, Guilleminault C, Vitiello MV (2004) Meta-analysis of quantitative sleep parameters from childhood to old age in healthy individuals: developing normative sleep values across the human lifespan. Sleep 27(7):1255-1273. https://doi.org/10.1093/sleep/ 27.7.1255\% JSleep

52. Bartels S, Quehl J, Berger M, Aeschbach D (2021) Exposure response-relationships between nocturnal aircraft noise and sleep disturbances in primary school children. In: Proceedings of 13th ICBEN congress on noise as a public health problem. Stockholm, Sweden, virtual congress

53. Brink M, Schäffer B, Vienneau D, Pieren R, Foraster M, Eze IC, Rudzik F, Thiesse L, Cajochen C, Probst-Hensch N, Röösli M, Wunderli JM (2019) Self-reported sleep disturbance from road, rail and aircraft noise: exposure-response relationships and effect modifiers in the SiRENE study. Int J Environ Res Public Health 16(21):4186. https://doi.org/10.3390/ijerph16214186

54. McGuire S, Müller U, Elmenhorst EM, Basner M (2016) Inter-individual Differences in the Effects of Aircraft Noise on Sleep Fragmentation. Sleep 39(5):1107-1110. https://doi.org/10. 5665/sleep.5764

55. Marks A, Griefahn B (2007) Associations between noise sensitivity and sleep, subjectively evaluated sleep quality, annoyance, and performance after exposure to nocturnal traffic noise. Noise Health 9(34):1-7. https://doi.org/10.4103/1463-1741.34698

56. Elmenhorst E-M, Müller U, Mendolia F, Quehl J, Aeschbach D (2016) Residents' attitude towards air traffic and objective sleep quality are related. In: Proceedings of the 45th international congress and exposition on noise control engineering (InterNoise 2016), pp 7744-7746

57. Quehl J, Müller U, Mendolia F (2017) Short-term annoyance from nocturnal aircraft noise exposure: results of the NORAH and STRAIN sleep studies. Int Arch Occup Environ Health 90(8):765-778. https://link.springer.com/article/10.1007\%2Fs00420-017-1238-7

58. Elmenhorst EM, Elmenhorst D, Wenzel J, Quehl J, Mueller U, Maass H, Vejvoda M, Basner M (2010) Effects of nocturnal aircraft noise on cognitive performance in the following morning: dose-response relationships in laboratory and field. Int Arch Occup Environ Health 83(7):743751. https://doi.org/10.1007/s00420-010-0515-5

59. Nassur AM, Lefèvre M, Laumon B, Léger D, Evrard AS (2019) Aircraft noise exposure and subjective sleep quality: the results of the DEBATS study in France. Behav Sleep Med 17(4):502-513. https://doi.org/10.1080/15402002.2017.1409224

60. Schreckenberg D (2018) Knowledge gaps concerning health impacts of environmental noise. In: Proceedings of Euronoise 2018. Heraklion, Crete-Greece, pp 985-991

61. Sánchez D, Naumann J, Porter N, Knowles A (2015) Current issues in aviation noise management: a non-acoustic factors perspective. In: Proceedings of the 22 nd international congress of sound and vibration. Florence, Italy 
62. Vader R (2007) Noise annoyance mitigation at airports by non-acoustic measures. Inventory and initial analysis. LVNL, Air Traffic Control the Netherlands, Amsterdam, The Netherlands

63. Haubrich J, Burtea NE, Flindell I, Hooper P, Hudson R, Rajé F, Schreckenberg D (2019) ANIMA D2.4-Recommendations on annoyance mitigation and implications for communication and engagement. Zenodo. https://doi.org/10.5281/zenodo.3988131

64. Hauptvogel D, Richard I, Haubrich J, Kuhlmann J, Heyes G, Benz S, Hooper P, Bartels S, Schreckenberg D (2021). ANIMA D3.9 - Engagement guideline. Zenodo. https://zenodo.org/ record/5517797

65. World Health Organiation (1997) Division of mental health and prevention of substance abuse. WHOQOL: measuring quality of life. World Health Organiation. https://apps.who.int/iris/han dle/10665/63482

66. EUROSTAT (2017) Final report of the expert group on quality of life indicators. http://ec.eur opa.eu/eurostat/web/products-statistical-reports/-/KS-FT-17-004

67. Roosien R, Schreckenberg D, Benz S, Kuhlmann J, Hooper P (2018) ANIMA-Public version of D3.1 Study to identify the gaps-Quality of Life indicators. Zenodo. https://doi.org/10.5281/ zenodo. 1549205

68. Lelij B, van der Bos L, Roelofs S (2020) Luchtvaart in Nederland, Draagvlakonderzoek onder het Nederlands publiek, meting 2020 (derde meting, tijdens COVID-19pandemie) https://www.rijksoverheid.nl/documenten/rapporten/2020/11/20/bijlage-6-rapportmotivaction-luchtvaart-in-nederland-draagvlakonderzoek-meting-2020

69. Klatte M, Spilski J, Mayerl J, Möhler U, Lachmann T, Bergström K (2017) Effects of aircraft noise on reading and quality of life in primary school children in Germany: results from the NORAH study. Environ Dev 49(4):390-424

70. International Civil Aviation Organisation (ICAO) (2008) Guidance on the balanced approach to aircraft noise management (2nd edn). Doc 9829 AN/451

71. Stewart J (2021) Think Local. Act Local. How airports can deliver for local communities. www.ukna.org.uk/uploads/4/1/4/5/41458009/delivering_for_local_airport_communities.pdf

Open Access This chapter is licensed under the terms of the Creative Commons Attribution 4.0 International License (http://creativecommons.org/licenses/by/4.0/), which permits use, sharing, adaptation, distribution and reproduction in any medium or format, as long as you give appropriate credit to the original author(s) and the source, provide a link to the Creative Commons license and indicate if changes were made.

The images or other third party material in this chapter are included in the chapter's Creative Commons license, unless indicated otherwise in a credit line to the material. If material is not included in the chapter's Creative Commons license and your intended use is not permitted by statutory regulation or exceeds the permitted use, you will need to obtain permission directly from the copyright holder.

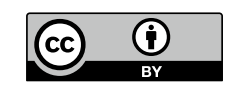

